\title{
Development and Evaluation of Dual Cross-Linked Pulsatile Beads for Chronotherapy of Rheumatoid Arthritis
}

\author{
Abanesh kumar Bansal and Vishal Pande \\ Department of Pharmaceutics, H.R. Patel Institute of Pharmaceutical Education and Research, Dhule, \\ Shirpur 425405, Maharashtra, India \\ Correspondence should be addressed to Vishal Pande; drvishalpande@gmail.com
}

Received 29 September 2012; Revised 19 November 2012; Accepted 24 November 2012

Academic Editor: Nayanabhirama Udupa

Copyright ( 2013 A. K. Bansal and V. Pande. This is an open access article distributed under the Creative Commons Attribution License, which permits unrestricted use, distribution, and reproduction in any medium, provided the original work is properly cited.

In the present investigation, pulsatile release beads were prepared by ionic gelation technique. Lornoxicam dual cross-linked beads were prepared by dropping dispersed phase of lornoxicam, pectin, and sodium alginate into the dispersion phase of different concentrations of calcium chloride solution followed by aluminium chloride solution. The formulated beads were further coated by Eudragit L \& S 100 in the ratio $1: 2 \mathrm{w} / \mathrm{w}$ in order to achieve desired lag time. In vitro release study showed lag time of 5-8 h before release of lornoxicam from the formulated beads. Thus, formulated dual cross-linked beads when administered at bed time may release lornoxicam when needed most for chronotherapeutics of early morning rheumatoid arthritis attacks in chronic patients.

\section{Introduction}

Lornoxicam is the nonsteroidal anti-inflammatory drug with potent anti-inflammatory and analgesic property [1]. Lornoxicam has greater potency than the other oxicam derivatives such as tenoxicam and piroxicam as cyclooxygenase (COX)-1 inhibitors [2,3]. Many diseases such as cardiovascular disease, bronchial asthma, rheumatoid arthritis, peptic ulcer, diabetes mellitus, and sleep disorders show circadian rhythms in their pathophysiology with prevailing night or early-morning manifestations. These diseases demand pulsatile drug delivery approach where the drug releases after depicting lag phase [4-6]. In this research work dual cross-linked pulsatile beads of lornoxicam were prepared by ionotropic gelation method using calcium chloride, aluminum chloride, pectin, and sodium alginate [7].

Alginate is a naturally occurring linear biopolymer which is found in brown seaweeds such as Laminaria hyperborean, Ascophyllum nodosum, and Macrocystis pyrifera. Alginate is found as mixed salt of various cations such as $\mathrm{Al}^{3+}, \mathrm{Mg}^{2+}$, $\mathrm{Sr}^{2+}, \mathrm{Ba}^{2+}$, and $\mathrm{Na}^{+}[8]$. Alginic acid containing $1,4^{\prime}$-linked $\mathrm{D}$-mannuronic acid and L-guluronic acid units was arranged in block as the same unit or random sequence of these units [9]. These arrangements form egg-box-like structure on contacting with divalent calcium ion and form hydrogel bead in aqueous solution of calcium chloride [10]. L-guluronic acid units of alginate bind with the divalent cation in solution and form gel structure. In this bead-like structure various biomolecules such as protein, peptide, cell, and drug can be entrapped. Sodium alginate controls or sustains the release of drug from gel matrix of the beads. The release of payload from alginate matrix can be achieved either by diffusion or alginate degradation or both [8].

Pectin is heterogeneous polysaccharides which are found in the cell wall of the plants. Pectin containing linear chain of poly(D-galacturonic acid) is bonded via 1,4-glycosidic linkage [11]. Solubility of pectin depends on the degree of methoxylation. As the degree of methoxylation increases, solubility of pectin decreases. Low methoxylated pectin has more capability to form insoluble rigid gel with divalent cation such as calcium ions cross-linked with galacturonic acid chain [12]. Pectin has pharmaceutical importance such as gelling or thickening agent and excipient for pharmaceutical purposes [13]. Hydration of pectin is deducted due to the increase of gelling property in the presence of acid, so incorporation of water reduces into the rigid gel structure. Pectin is not digested in stomach by enzyme such as proteases and amylase but it is sensitive to the enzyme which is secreted by 
microflora in the colon [14]. In this research work we reveal the application of dual cross-linked pulsatile beads to control the drug delivery. The disorders such as cardiovascular disease, bronchial asthma, rheumatoid arthritis, peptic ulcer, and so forth demand the pulsatile delivery of therapeutic agent. Natural polymers such as sodium alginate and pectin were used to formulate the dual cross-linked pulsatile beads by ionotropic gelation method using lornoxicam as a model drug. These polymers swell at higher $\mathrm{pH}$ and release the drug by diffusion or degradation mechanism in sustained release or burst release after predetermined lag time. These beads fill in the capsule and they are coated with Eudragit S100 \& L100 as reported in literature. For achieving the required lag time, capsule was coated with Eudragit S100 \& Eudragit L100 in proportion of $1: 2$ ratio which have the maximum solubility at $6.8 \mathrm{pH}$. Therefore, this combination of two polymers was selected for coating of dual cross-linked beads.

\section{Materials and Methods}

2.1. Material. Lornoxicam was obtained as a gift sample from Glenmark Pharmaceutical Ltd. (Nashik, India). Sodium alginate and pectin (LOBA Chemie, Mumbai, India), Eudragit S100 and Eudragit L100 (Research Lab, Fine chemicals, Mumbai, India), Calcium chloride and Aluminum chloride anhydrous (Merck specialties private limited, Mumbai, India). All other were reagents used in this study were of analytical grade.

2.2. Solubility of Lornoxicam in Different $p H$ Conditions. The solubility study was conducted to depict the solubility of lornoxicam at varying $\mathrm{pH}$ conditions. Saturated solutions of lornoxicam were prepared by dispersing an excess amount of drug in the buffer with $\mathrm{pH} 1.2,6.8,7.4,12$, and 13. The samples were subjected to orbital shaker (Remi Instrument Ltd. CIS-24) for 72 hours to aid maximum dissolution of the drug. After the incubation period, clear saturated solutions were obtained by filtration $(0.45 \mu \mathrm{m}$ Millipore filter paper) and the concentration of the drug was determined spectrophotometrically (UV-1800 PC Shimadzu, Japan) at the corresponding wavelengths, after the appropriate dilution in the corresponding $\mathrm{pH}$ buffer.

\subsection{Preparation of Single Cross-Linked $\mathrm{Ca}^{++}$Pectin-Alginates} Beads. Lornoxicam was dispersed in distilled water and sonicated for $45 \mathrm{sec}$ for reducing the particle side of drug (Table 1). Preweighted amount of pectin and sodium alginate were completely dissolved into the above solution and stirred for few minutes. The uniform dispersion was carried out by dispersion dropping with 25 gauge needles into 5\% calcium chloride solution and stirred for $10 \mathrm{~min}$ for cross-linking of pectin and alginate. After the required cross-linking time, beads were filtered, washed with $50 \mathrm{~mL}$ double distilled water, and dried in the incubator at $40^{\circ} \mathrm{C}$ till the weight is constant.

\subsection{Preparation of Dual Cross-Linked $\mathrm{Ca}^{2+} / \mathrm{Al}^{3+}$ Pectin-} Alginates Beads. Prepared $\mathrm{Ca}^{2+}$ single cross-linked pectin alginate beads (P6 and P7) were immediately transferred into a $50 \mathrm{~mL}$ solution of $5 \%$ aluminum chloride (\% w/v) for 5 min and then the $\mathrm{Ca}^{2+}$ and $\mathrm{Al}^{3+}$ dual cross-linked beads were separated by filtration, washed thrice with $50 \mathrm{~mL}$ double distilled water, air dried, and finally vacuum-dried at $40^{\circ} \mathrm{C}$ till constant weight.

2.5. Preparation of Enteric-Coated Capsule. Enteric-coated gelatin capsules were prepared by manual dipping technique. Entire hard gelatin capsule was dipped in $2 \% \mathrm{w} / \mathrm{v}$ Eudragit S100 \& Eudragit L100 (1:2 ratio) in methanol. The coated gelatin capsule was dried at $40^{\circ} \mathrm{C}$ for $30 \mathrm{~min}$. Equivalent amount $(8 \mathrm{mg})$ of dual cross-linked beads were filled along with $10 \%$ magnesium stearate as a lubricant in size 2 of enteric-coated capsule.

\section{In Vitro Characterization of Formulated Pectin-Alginate Beads}

3.1. Particle Size Analysis. Particle size analysis of dual cross-linked pectin alginate was performed using motic microscopy. Formulated 20 beads of each batches were randomly selected and observed in motic DMWB2-223 digital microscope fitted with 1/3 CCD camera imaging accessory and using Motic Images 2000 (1.3 Version) image analysis software.

3.2. Determination of Yield. The production yield of prepared dual cross-linked pectin-alginate beads was calculated using the weight of final product after drying with respect to the initial total weight of the drug and polymer used for preparation of beads and percent yields were calculated as per the following formula:

$$
\% \text { Yield }=\frac{P m}{T m} \times 100
$$

where $P m$ and $T m$ are practical yield and theoretical yield of formulation, respectively.

3.3. Drug Content. For determining drug content, weighed amount $(35 \mathrm{mg})$ of dual cross-linked pectin-alginate beads were placed into the $100 \mathrm{~mL}$ of $0.1 \mathrm{~N} \mathrm{NaoH}$ solution of each formulation and stirred the solution with mechanical stirrer then filtered the solution and analyzed spectrophotometrically at $377.5 \mathrm{~nm}$ in UV spectrophotometer [15]. \% Entrapment efficiency was estimated by

$$
\text { Entrapment Efficiency }(\%)=\frac{A q}{T q} \times 100,
$$

where $A q$ and $T q$ are actual quantity and theoretical quantity of present in formulation, respectively.

3.4. Swelling Study. Swelling behavior of pectin alginate dual cross-linked beads was studied by using digital caliper [16, 17]. All formulated batches were placed in $1.2 \mathrm{pH}$ buffer and $6.8 \mathrm{pH}$ buffer in Petridis and the diameter of 10 beads was measured after and before the swelling of beads at 
TABLE 1: Composition of single and dual cross-linked beads formulation.

\begin{tabular}{|c|c|c|c|c|c|c|c|}
\hline \multirow[b]{2}{*}{ Batch code } & \multicolumn{4}{|c|}{ Dispersion phase } & \multicolumn{3}{|c|}{ Dispersion medium } \\
\hline & $\begin{array}{l}\text { Lornoxicam } \\
(\mathrm{mg})\end{array}$ & $\begin{array}{c}\text { Sodium alginate } \\
(\mathrm{mg})\end{array}$ & $\begin{array}{c}\text { Pectin } \\
(\mathrm{mg})\end{array}$ & $\begin{array}{c}\text { Distilled water } \\
(\mathrm{mL})\end{array}$ & $\begin{array}{l}\mathrm{CaCl}_{2} \\
(\% \mathrm{w} / \mathrm{v})\end{array}$ & $\begin{array}{l}\mathrm{AlCl}_{3} \\
(\% \mathrm{w} / \mathrm{v})\end{array}$ & $\begin{array}{l}\text { Cross-linking time } \\
\text { (min.) }\end{array}$ \\
\hline $\mathrm{P} 1$ & 50 & 400 & 100 & 10 & 5 & - & 10 \\
\hline $\mathrm{P} 2$ & 50 & 350 & 150 & 10 & 5 & - & 10 \\
\hline P3 & 50 & 300 & 200 & 10 & 5 & - & 10 \\
\hline $\mathrm{P} 4$ & 50 & 450 & 50 & 10 & 5 & - & 10 \\
\hline P5 & 50 & 250 & 250 & 10 & 5 & - & 10 \\
\hline P6 & 50 & 400 & 100 & 10 & 5 & 5 & 10 \\
\hline P7 & 50 & 450 & 50 & 10 & 5 & 5 & 10 \\
\hline P8 & 50 & 400 & 100 & 10 & 5 & - & 15 \\
\hline P9 & 50 & 400 & 100 & 10 & 5 & - & 20 \\
\hline
\end{tabular}

TABLE 2: Solubility of lornoxicam at different $\mathrm{pH}$ conditions.

\begin{tabular}{lccc}
\hline Sr. no. & $\mathrm{pH}$ & Wavelength $(\mathrm{nm})$ & Solubility $(\mathrm{mg} / \mathrm{mL})$ \\
\hline 1 & 1.2 & 365.0 & 0.049 \\
2 & 6.8 & 378.0 & 0.082 \\
3 & 7.4 & 377.0 & 0.156 \\
4 & 12 & 376.5 & 8.96 \\
5 & 13 & 377.5 & 9.76 \\
\hline
\end{tabular}

predetermined time interval, and swelling (\%) was estimated according to the following relationship:

$$
\text { Swelling }(\%)=\frac{D_{t}-D_{o}}{D_{o}} \times 100,
$$

where $D_{o}$ and $D_{t}$ are the initial diameter of the beads and the diameter of the beads at a given time, respectively.

3.5. Scanning Electron Microscopy (SEM). Morphological analysis or surface topography of dual cross-linked pectin alginate beads was carried out using scanning electron microscope. Beads were coated with thin palladium layer and surface topography was analyzed at $10 \mathrm{KV}$ acceleration voltages using scanning electron microscope (JEOL JSM6390, Tokyo, Japan).

3.6. Fourier Transforms Infrared (FTIR) Study. FTIR spectra of lornoxicam, physical mixture, and final formulation were recorded with FTIR spectrophotometer (IR IFFINITY$1 \mathrm{CE}$, Shimadzu corps, Japan) equipped with pyroelectric detector using dispersion method. The FTIR measurements were performed in the scanning range of $4,000-400 \mathrm{~cm}^{-1}$ at ambient temperature. The spectra were saved using IR solution software. All samples were softly grounded before analysis.

3.7. Differential Scanning Colorimetry (DSC). DSC thermograms of lornoxicam, physical mixture, and pectin alginate beads were recorded using differential scanning colorimeter (DSC-60, Shimadzu, Japan). Each sample (5-10 mg) was scanned in pierced $\mathrm{Al}$ pans. The measurement was performed between 50 and $400^{\circ} \mathrm{C}$ at heating rate $10^{\circ} \mathrm{C} / \mathrm{min}$.
3.8. In Vitro Dissolution Studies. USP dissolution apparatus I (Dissolution test TDT-08L plus, Electrolab, India) was used to perform the release of dual cross-linked beads. Basket was rotated at $50 \mathrm{rpm}$ and temperature maintained at $37.0 \pm 0.5^{\circ} \mathrm{C}$. Dissolution studies were carried out in $900 \mathrm{~mL}$ of $0.1 \mathrm{~N}$ hydrochloric acid buffer, $1.2 \mathrm{pH}$ for 2 hour and $\mathrm{pH} 6.8$ phosphate buffer for remaining hours. After 2 hours $1.2 \mathrm{pH}$ hydrochloric acid buffer was replaced with 6.8 $\mathrm{pH}$ phosphate buffer and study was carried out for 12 hours. Samples $(5 \mathrm{~mL})$ were withdrawn and filtered. The withdrawal sample was replaced with equal volume of fresh medium at regular time interval. The amount of drug release was analyzed spectrophotometrically at $378 \mathrm{~nm}$.

\section{Results and Discussion}

4.1. Solubility of Lornoxicam at Different $p H$ Ranges at Room Temperature. Solubility of lornoxicam increased substantially with an increase in the $\mathrm{pH}$ of media (Figure 1 and Table 2). It was found to be much higher in alkaline $\mathrm{pH}$ compared to neutral and acidic one. The solubility was found to be $0.049 \mathrm{mg} / \mathrm{mL}, 0.082 \mathrm{mg} / \mathrm{mL}, 0.156 \mathrm{mg} / \mathrm{mL}, 8.96 \mathrm{mg} / \mathrm{mL}$, and $9.76 \mathrm{mg} / \mathrm{mL}$ in media with $\mathrm{pH} 1.2, \mathrm{pH} 6.8, \mathrm{pH} 7.4, \mathrm{pH} 12$, and $\mathrm{pH} 13$, respectively. Lornoxicam showed the maximum solubility in $\mathrm{pH} 13$ as compared to the other $\mathrm{pH}$ (Table 2), it is required to find the actual concentration of lornoxicam present in the formulated dual cross-linked beads.

4.2. Physical Properties of the Composite Pectin Alginate Beads. Morphological characteristics of pectin alginate beads are demonstrated in Table 3. Average diameter of beads deviated from $1.06 \pm 0.07 \mathrm{~mm}$ to $1.30 \pm 0.03 \mathrm{~mm}$ for different batches. Size of formulated beads increases by increasing the content 
TABLE 3: Characteristics of composite pectin alginate beads.

\begin{tabular}{lccccc}
\hline Batch code & $\begin{array}{c}\text { Production } \\
\text { yield }(\%)\end{array}$ & $\begin{array}{c}\text { Entrapment } \\
\text { efficiency }\end{array}$ & $\begin{array}{c}\text { Average } \\
\text { diameter }(\mathrm{mm})\end{array}$ & $\begin{array}{c}\text { \% Swelling } \\
(6.8 \mathrm{pH})\end{array}$ & $\begin{array}{c}\text { \% Swelling } \\
(1.2 \mathrm{pH})\end{array}$ \\
\hline P1 & $85.30 \pm 0.70$ & $82.95 \pm 1.42$ & $1.15 \pm 0.06$ & $200.5 \pm 32.4$ & $31.5 \pm 12.3$ \\
P2 & $91.38 \pm 1.26$ & $72.93 \pm 1.20$ & $1.08 \pm 0.05$ & $175.3 \pm 27.0$ & $40.8 \pm 9.70$ \\
P3 & $87.69 \pm 2.39$ & $74.89 \pm 1.32$ & $1.06 \pm 0.07$ & $158.9 \pm 19.5$ & $42.3 \pm 13.0$ \\
P4 & $91.49 \pm 1.63$ & $79.37 \pm 1.55$ & $1.11 \pm 0.06$ & $293.8 \pm 20.5$ & $24.2 \pm 9.13$ \\
P5 & $88.41 \pm 0.57$ & $76.69 \pm 3.57$ & $1.07 \pm 0.05$ & $114.4 \pm 22.6$ & $55.2 \pm 12.6$ \\
P6 & $93.30 \pm 0.76$ & $83.24 \pm 1.05$ & $1.30 \pm 0.03$ & $57.0 \pm 5.1$ & $29.4 \pm 9.21$ \\
P7 & $92.70 \pm 1.46$ & $83.04 \pm 1.57$ & $1.20 \pm 0.03$ & $72.6 \pm 9.4$ & $25.5 \pm 5.49$ \\
P8 & $88.36 \pm 1.37$ & $80.65 \pm 1.95$ & $1.16 \pm 0.04$ & $98.6 \pm 11.25$ & $25.6 \pm 3.55$ \\
P9 & $90.69 \pm 0.98$ & $83.01 \pm 1.36$ & $1.18 \pm 0.07$ & $81.54 \pm 6.28$ & $28.7 \pm 5.11$ \\
\hline
\end{tabular}

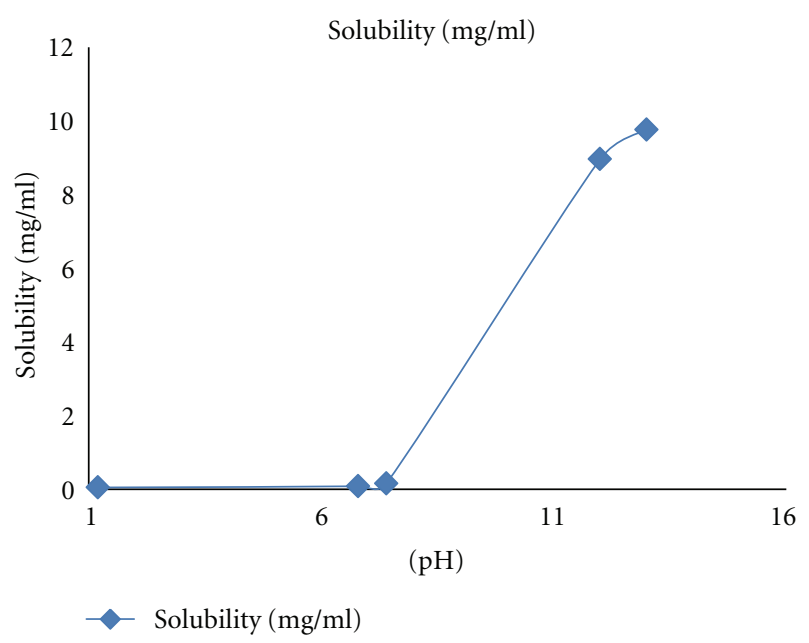

FIGURE 1: Graphical representation of lornoxicam solubility study at different $\mathrm{pH}$ ranges at room temperature.

of sodium alginate and cross-linking time. Dual cross-linked beads have more size than single cross-linked beads. Prepared pectin alginate beads are observed to be spherical in shape under the optical microscope. Dual cross-linked beads are found to be more spherical than the single cross-linked beads. It was observed that trivalent ion $\mathrm{Al}^{3+}$ has better cross-linking with sodium alginate than divalent ion $\mathrm{Ca}^{2+}$.

4.3. Fourier Transformed Infrared (FTIR) Study. FTIR spectra of pure drug, physical mixture and formulation are reported in Figure 2. FTIR spectra of pure lornoxicam show the peak around $3066 \mathrm{~cm}^{-1}$ of $-\mathrm{NH}$ group. It shows sharp peak at $1647 \mathrm{~cm}^{-1}$ of primary amide and 1598,1550 of secondary amide. FTIR spectra show at $831 \mathrm{~cm}^{-1}$ (aromatic bending), $1147,1327,1384 \mathrm{~cm}^{-1}$ (-SO $\mathrm{SO}_{2}$ group) and $790 \mathrm{~cm}^{-1}(\mathrm{C}-\mathrm{Cl}$ group). FTIR spectra of pure drug, physical mixture, and formulation are compared. It showed that there is no interaction between the drug and the polymer. So, the drug and polymer are compatible.

4.4. Differential Scanning Colorimetry (DSC). DSC analysis of pure drug, physical mixture and formulation are showed

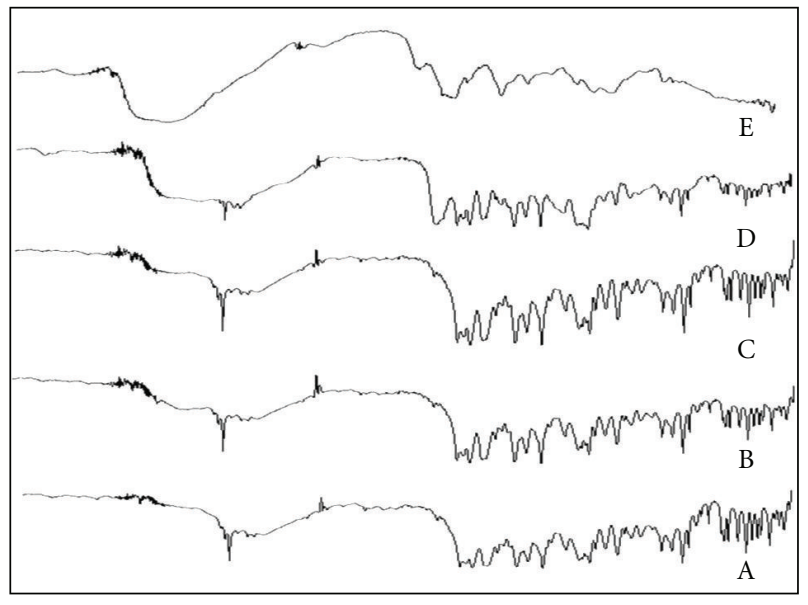
A: lornoxicam
B: pectin and lornoxicam
D: pectin, sodium alginate, and
C: sodium alginate and lornoxicam
lornoxicam
E: formulation

FIgURE 2: Shows the FTIR spectra of (A) lornoxicam; (B) pectin, and lornoxicam; (C) sodium alginate and lornoxicam; (D) pectin, sodium alginate, and lornoxicam; (E) formulation.

in Figure 3. DSC themogram of lornoxicam showed sharp exothermic peak at $232^{\circ} \mathrm{C}$ due to its melting process (Figure 3(a)). Drug melting peak is present even in its physical mixture with pectin and sodium alginate. However, the small lowering of peak temperature of related enthalpy variation was observed due to the mixture of component. Physical mixture of lornoxicam and pectin, lornoxicam, and sodium alginate showed the peak temperature at $227^{\circ} \mathrm{C}$ and $234^{\circ} \mathrm{C}$ (Figures 3(b) and 3(c)). Pectin alginate beads show peak at $235^{\circ} \mathrm{C}$ (Figure $3(\mathrm{~d})$ ). It indicates that no interaction found between drug and polymers.

4.5. Production Yield and Entrapment Efficiency. Dual crosslinked pectin alginate beads formulation batches P6 and P7 have high drug entrapment efficiency and production yield than the single cross-linking beads formulation P1, P2, P3, P4, P5 have cross-linking time $10 \mathrm{~min}$. But P1 and P4 formulation have high entrapment efficiency amongst 


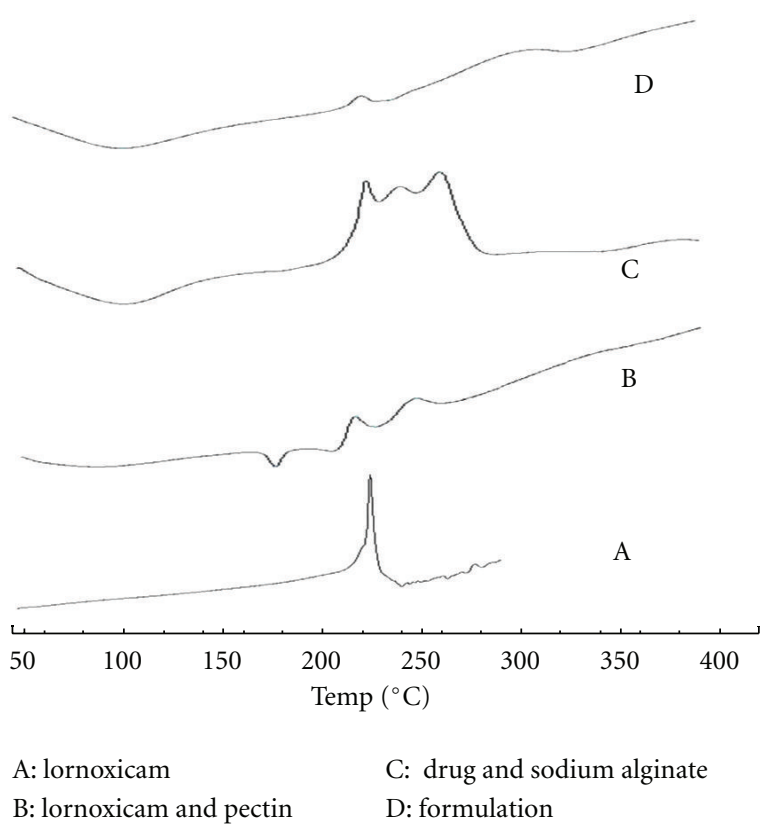

FIgURE 3: DSC thermograms of (A) lornoxicam (B) lornoxicam, and pectin $(\mathrm{C})$ drug and sodium alginate $(\mathrm{D})$ formulation.

these five formulations due to concentration of sodium alginate, suggesting when the concentration of sodium alginate increases, the entrapment efficiency also increases due to more cross-linking between the sodium alginate and crosslinking agents. It indicates that trivalent ion $\mathrm{Al}^{3+}$ has greater reactivity than divalent ion $\mathrm{Ca}^{2+}$ with carboxyl group of $\mathrm{L}$ guluronic acid units of sodium alginate and pectin. They form more rigid gel matrix structure of beads. Therefore the drug loss gets reduced resulting in better entrapment efficiency.

4.6. Effect of Cross-Linking Time. Entrapment efficiency and production yield increase by increasing the cross-linking time (Figure 4). Longer the cross-linking time 10-20 min amount of lornoxicam released from pectin-alginate, beads were reduced and dual cross-linked beads which have crosslinking time $10 \mathrm{~min}$ show more sustained release of drug from the pectin alginate beads than single cross-linked beads which have $10 \mathrm{~min}$ cross-linking time. Formulation of dual cross-linked beads overcomes the burst release from the formulation. The average size of dual cross-linked beads is found to be more than single cross-linked beads formulation. It suggests that trivalent ion has better cross-linking than divalent ion.

4.7. Swelling Study. Swelling property was mostly affected by the concentration of sodium alginate, pectin, and crosslinking of beads. As the concentration of sodium alginate increases the swelling capacity of beads increases considerably while the swelling capacity is rendered by crosslinking (Figure 5). Formulation P1, P4 and P6, P7 have same concentration of sodium alginate but $\mathrm{P} 1$ and $\mathrm{P} 4$ show higher swelling ability compared to P6 and P7 due to the cross-linking. It is observed that the dual cross-linking beads

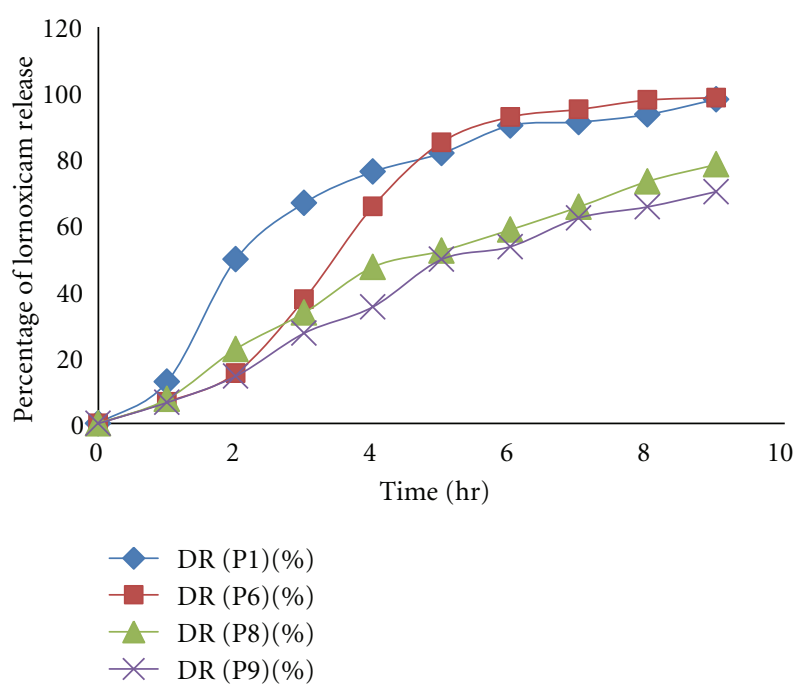

FIGURE 4: Effect of cross-linking time on release of lornoxicam from pectin alginate beads.

have lower degree of swelling ability than single cross-linked beads. Also, as the concentration of sodium alginate $450 \mathrm{mg}$ in formulation $\mathrm{P} 4$ reduces to $250 \mathrm{mg}$ in P5, the percentage swelling get reduced from $293.8 \pm 20.5$ to $114.4 \pm 22.6$ (Table 3). Swelling ability of beads was observed lesser in $\mathrm{pH} 1.2$ compared to $\mathrm{pH} 6.8$.

4.8. Scanning Electron Microscopy. SEM images of the formulated beads at different magnifications were shown in Figure 6. Surface morphology of pectin alginate beads, studied by SEM, indicated that the dual cross-linked beads have more rigid surface with cracks compared to the single cross-linked beads. The dual cross-linked beads are more spherical in shape compared to the single cross-linked beads as shown in SEM image.

4.9. In Vitro Dissolution Studies. USP dissolution apparatus 1 (Basket type) was used to perform the drug release study at $50 \mathrm{rpm}$ and temperature maintained at $37 \pm 0.5^{\circ} \mathrm{C}$. In vitro drug release studies of formulation fabricated with enteric coated as well as uncoated gelatin capsule shell were performed. The bare pectin alginate beads showed immediate drug release while, when the beads are filled in the enteric gelatin capsule there was a $\mathrm{pH}$ dependent drug release after the dissolution of the capsule shell. Drug release was inversely related to the concentration of sodium alginate and crosslinking of beads. The decrease in drug release resulted in increase in sodium alginate concentration and increasing the cross-linking time. With the increase in the concentration of the Eudragit S100 and Eudragit L100 in the coating solution there is considerable increase in the lag time for drug release, namely, when $2 \%$ Eudragit was used for coating. The lag time was observed to be $6 \mathrm{hrs}$ while $4 \%$ and $6 \%$ Eudragit showed lag time $8 \mathrm{hrs}$ to $9 \mathrm{hrs}$, respectively. Hence, we optimized the Eudragit concentration as 2\% to get the desired lag time for the drug release (Figure 7). The effective sustained release was obtained from different formulations. The uncoated 


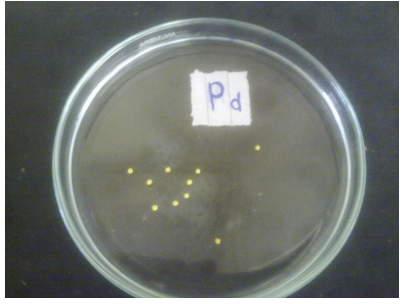

(a)

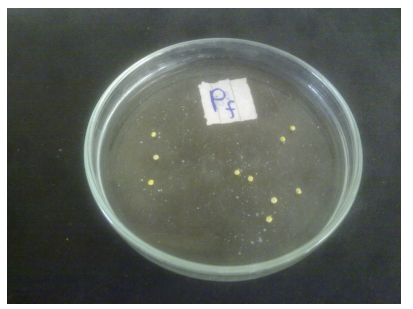

(e)

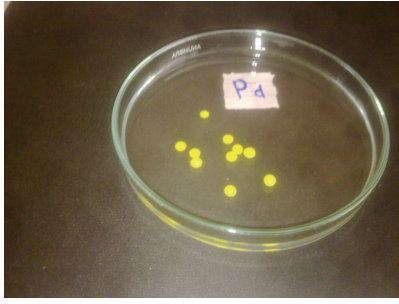

(b)

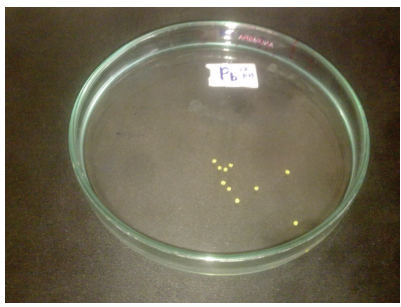

(f)

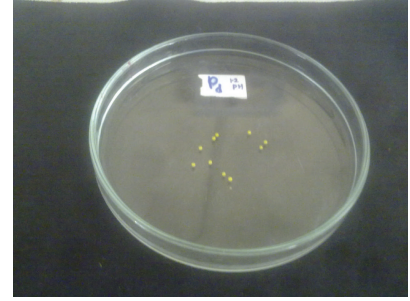

(c)

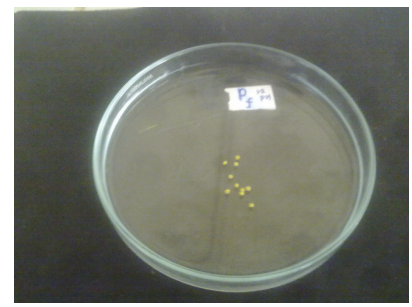

(g)

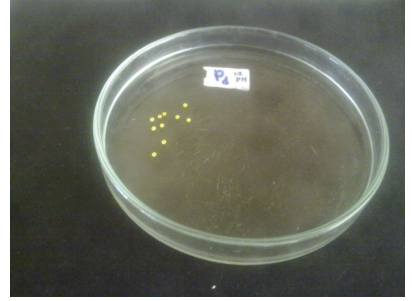

(d)

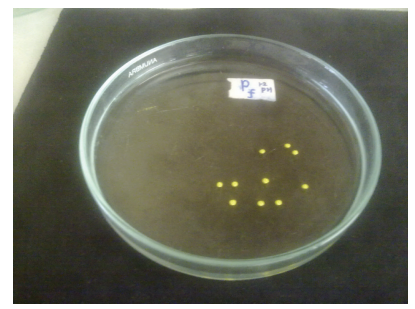

(h)

Figure 5: \% swelling of single ((a) and (b) in $6.8 \mathrm{pH}$ and (c) and (d) in $1.2 \mathrm{pH})$ and dual ((e) and (f) in $6.8 \mathrm{pH}$ and $(\mathrm{g})$ and $(\mathrm{h})$ in $1.2 \mathrm{pH})$ cross-linked beads before ((a), (c), (e), and (g)) and after 2 hours ((b), (d), (f), and (h)).

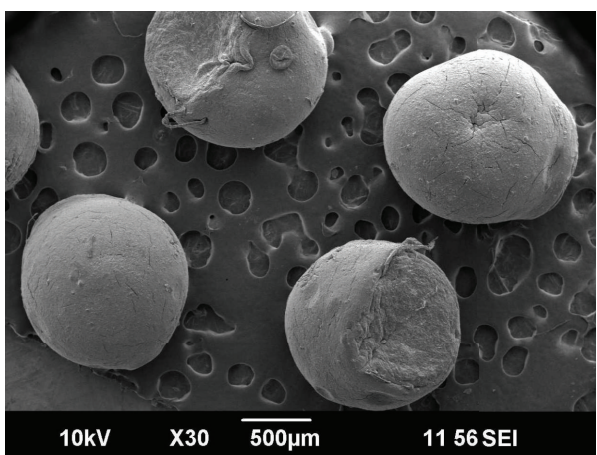

(a)

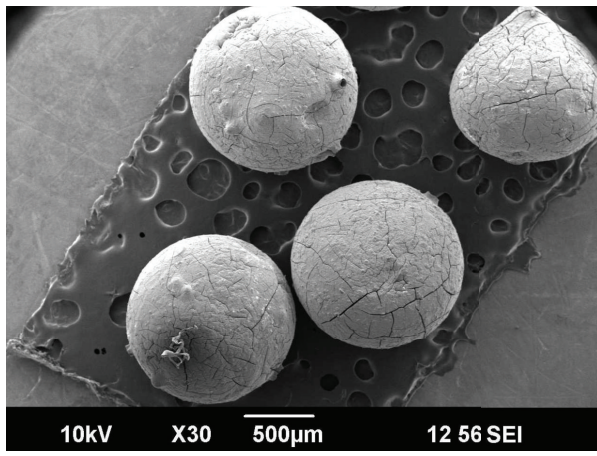

(c)

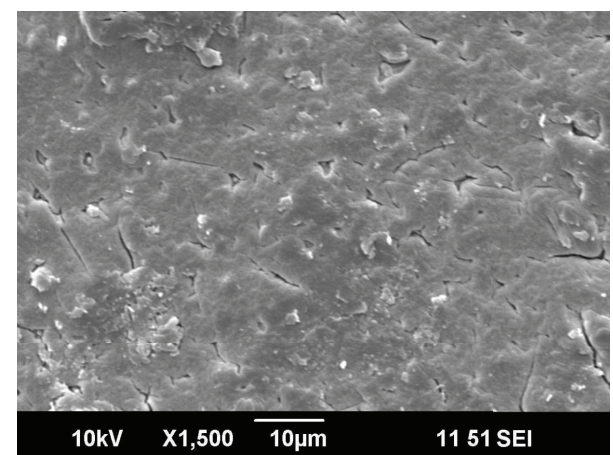

(b)

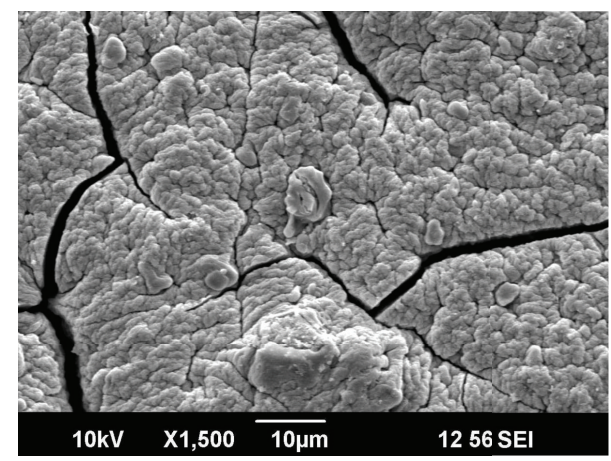

(d)

FiguRE 6: SEM images of single ((a) and (b)) and dual ((c) and (d)) cross-linked beads at different magnifications.

formulations P1, P4, P6, and P7 showed much sustained drug release than formulation P2, P3, and P5. Moreover, amongst this formulation $\mathrm{P} 6$ and $\mathrm{P} 7$ gave more sustained drug release due to the formation of the rigid gel structure dual with $\mathrm{AlCl}^{3+}$ which reduces the drug release from gel matrix of beads, so overcome the burst release of drug from the pectin alginate beads by formulating the dual cross-linked beads.

The uncoated formulation P2, P3, and P5 gave burst release in 2 hrs $87.11 \%, 77.16 \%$, and $74.87 \%$ after the swelling of beads (Figure 8 ). In the case of enteric-coated formulation 


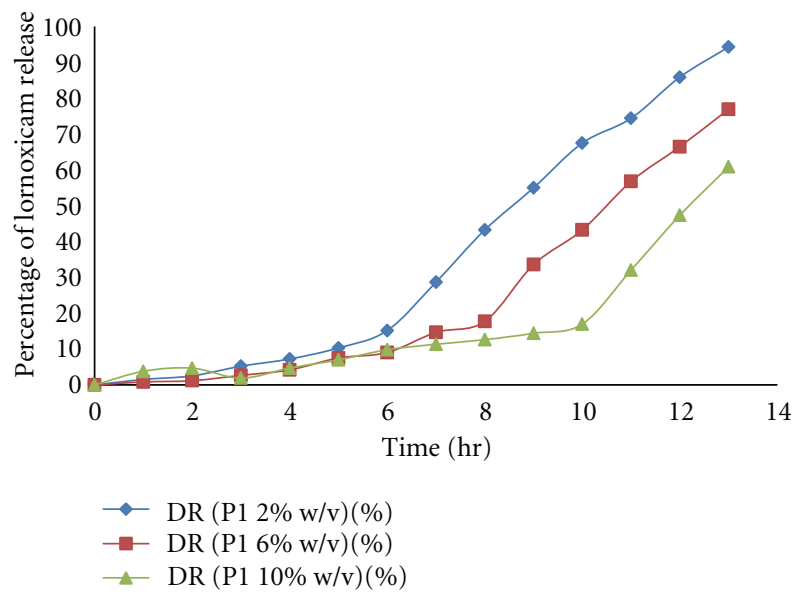

Figure 7: Effect of Eudragit solution concentration on lag time.
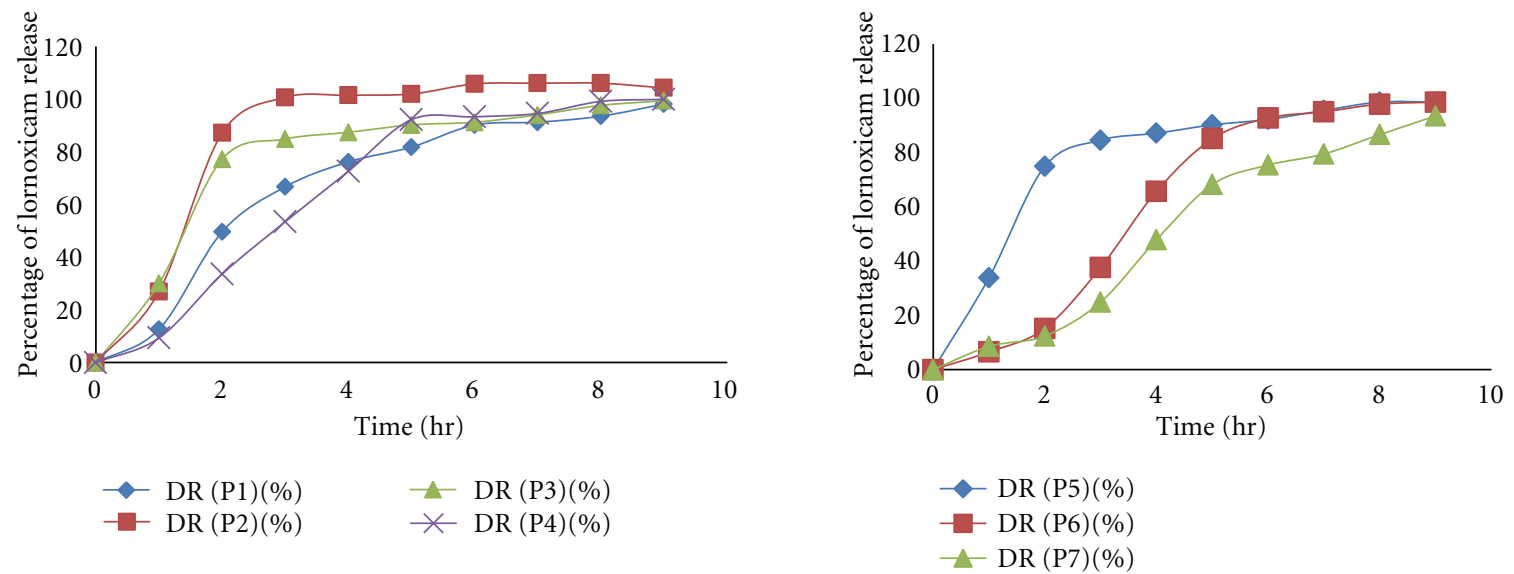

FIGURE 8: Release profile of lornoxicam from uncoated pectin alginate beads.
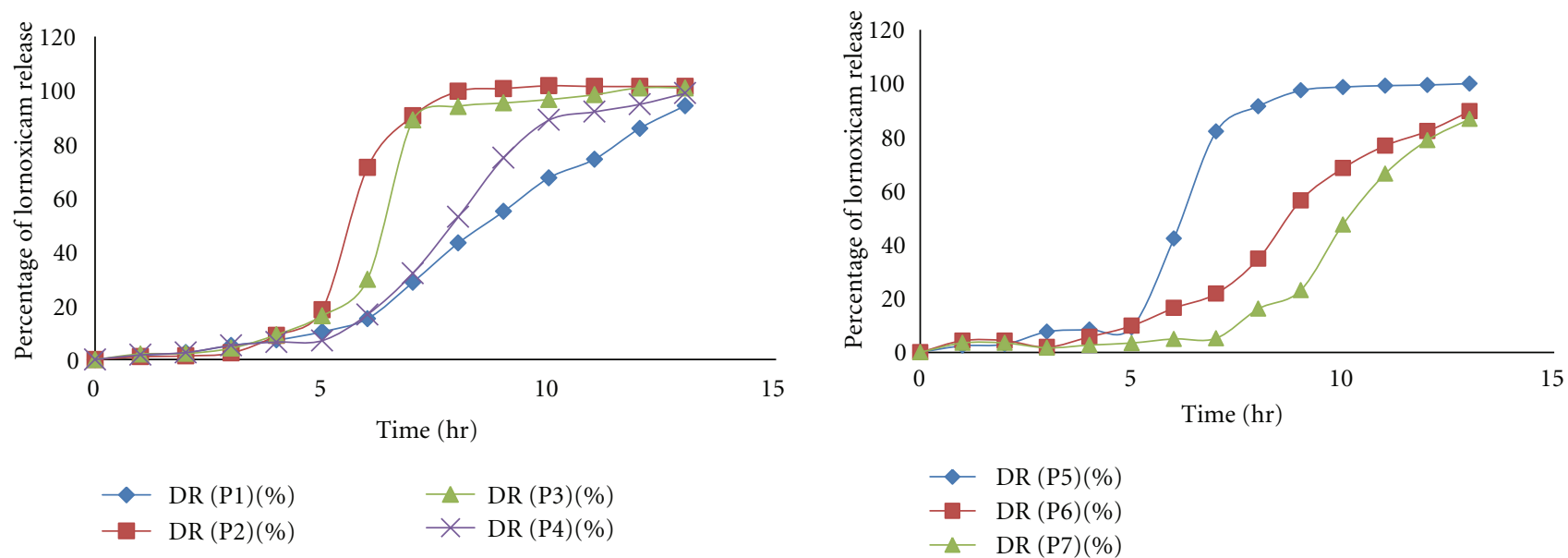

FIGURE 9: Release profile of lornoxicam from coated pectin alginate beads. 
$\mathrm{P} 1$ and P4 formulation depicted $6 \mathrm{hr}$ lag time and P3, P4, and P5 formulation show lag time $5 \mathrm{hr}$ because of lesser concentration of sodium alginate but the formulation P6 and P7 demonstrated $7 \mathrm{hrs}$ to $8 \mathrm{hrs}$ lag time due to dual crosslinking with $\mathrm{AlCl}^{3+}$ (Figure 9). In case of dual cross-linking rigid gel structure is formed which reduce the diffusion of drug from beads and increase the lag time of formulation.

\section{Conclusion}

Dual cross-linked pectin alginate beads obtained by ionotropic gelation method were evaluated in the in vitro dissolution experiment. The in vitro drug release from pectin alginate beads depends on the concentration of sodium alginate, cross-linking ion, and cross-linking time. In case of dual cross-linking drug release, after $7 \mathrm{hrs}$ to $8 \mathrm{hrs}$ lag time which administered at bed time may release lornoxicam when needed most for chronotherapeutics of early morning rheumatoid arthritis attacks in chronic patients. Dual crosslinked beads can be proposed as a promising approach for the design of pulsatile drug delivery system for rheumatoid arthritis.

\section{Acknowledgments}

The authors are thankful to the sophisticated test and instrumentation centre, Kochi for help in SEM studies. The Management and Principal (H.R. Patel Institute of Pharmaceutical Education and Research, Shirpur) are gratefully acknowledged for providing facilities to carry out this research work.

\section{References}

[1] Merck, The Merck Index, Merck Research Laboratories, White House Station, NJ, USA, 1996.

[2] H. Berry, H. A. Bird, C. Black et al., "A double blind, multicentre, placebo controlled trial of lornoxicam in patients with osteoarthritis in the hip and knee," Annals of the Rheumatic Diseases, vol. 51, no. 2, pp. 238-242, 1992.

[3] A. Goregaonkar, K. J. Mathiazhagan, R. R. Shah et al., "Comparative assessment of the effectiveness and tolerability of lornoxicam $8 \mathrm{mg}$ BID and diclofenac $50 \mathrm{mg}$ TID in adult indian patients with osteoarthritis of the hip or knee: a 4-week, doubleblind, randomized, comparative, multicenter study, Current Therapeutic Research, vol. 70, no. 1, pp. 56-68, 2009.

[4] A. Maroni, L. Zema, M. D. D. Curto, G. Loreti, and A. Gazzaniga, "Oral pulsatile delivery: rationale and chronopharmaceutical formulations," International Journal of Pharmaceutics, vol. 398, no. 1-2, pp. 1-8, 2010.

[5] G. S. Sharma, M. V. Srikanth, M. U. Uhumwangho, K. S. K. Phani, and K. V. Ramana, "Recent trends in pulsatile drug delivery system: a review," International Journal of Drug Delivery, vol. 2, no. 3, pp. 200-212, 2010.

[6] M. Rajput, R. Sharma, S. Kumar, F. Jamil, N. Sissodia, and S. Sharma, "Pulsatile drug delivery system: a review," International Journal of Research in Pharmaceutical and Biomedical Sciences, vol. 3, pp. 118-124, 2012.

[7] T. Ostberg, E. M. Lund, and C. Graffner, "Calcium alginate matrices for oral multiple unit administration IV. Release characteristics in different media," International Journal of Pharmaceutics, vol. 112, no. 3, pp. 241-248, 1994.

[8] M. George and T. E. Abraham, "Polyionic hydrocolloids for the intestinal delivery of protein drugs: alginate and chitosan-a review," Journal of Controlled Release, vol. 114, no. 1, pp. 1-14, 2006.

[9] R. Gong, C. Li, S. Zhu, Y. Zhang, Y. Du, and J. Jiang, "A novel $\mathrm{pH}$-sensitive hydrogel based on dual crosslinked alginate/ $\mathrm{N}-\alpha$ glutaric acid chitosan for oral delivery of protein," Carbohydrate Polymers, vol. 85, no. 4, pp. 869-874, 2011.

[10] A. Kikuchi, M. Kawabuchi, M. Sugihara, Y. Sakurai, and T. Okano, "Pulsed dextran release from calcium-alginate gel beads," Journal of Controlled Release, vol. 47, no. 1, pp. 21-29, 1997.

[11] V. R. Sinha and R. Kumria, "Polysaccharides in colon-specific drug delivery," International Journal of Pharmaceutics, vol. 224, no. 1-2, pp. 19-38, 2001.

[12] J. Fell, M. Ashford, D. Attwooda, H. Sharmab, and P. Woodhead, "Studies on pectin formulations for colonic drug delivery," Journal of Controlled Release, vol. 30, no. 3, pp. 225-232, 1994.

[13] A. Wade and P. J. Weller, Handbook of Pharmaceutical Excipients, A Joint Publication of The Pharmaceutical Press and American Pharmaceutical Association, London, UK, 1994.

[14] P. Sriamornsak, "Investigation of pectin as a carrier for oral delivery of proteins using calcium pectinate gel beads," International Journal of Pharmaceutics, vol. 169, no. 2, pp. 213-220, 1998.

[15] A. R. Tekade and S. G. Gattani, "Development and evaluation of pulsatile drug delivery system using novel polymer," Pharmaceutical Development and Technology, vol. 14, no. 4, pp. 380-387, 2009.

[16] T. Pongjanyakul and S. Puttipipatkhachorn, "Xanthan-alginate composite gel beads: molecular interaction and in vitro characterization," International Journal of Pharmaceutics, vol. 331, no. 1, pp. 61-71, 2007.

[17] A. Halder, S. Maiti, and B. Sa, "Entrapment efficiency and release characteristics of polyethyleneimine-treated or untreated calcium alginate beads loaded with propranolol-resin complex," International Journal of Pharmaceutics, vol. 302, no. 1-2, pp. 84-94, 2005. 

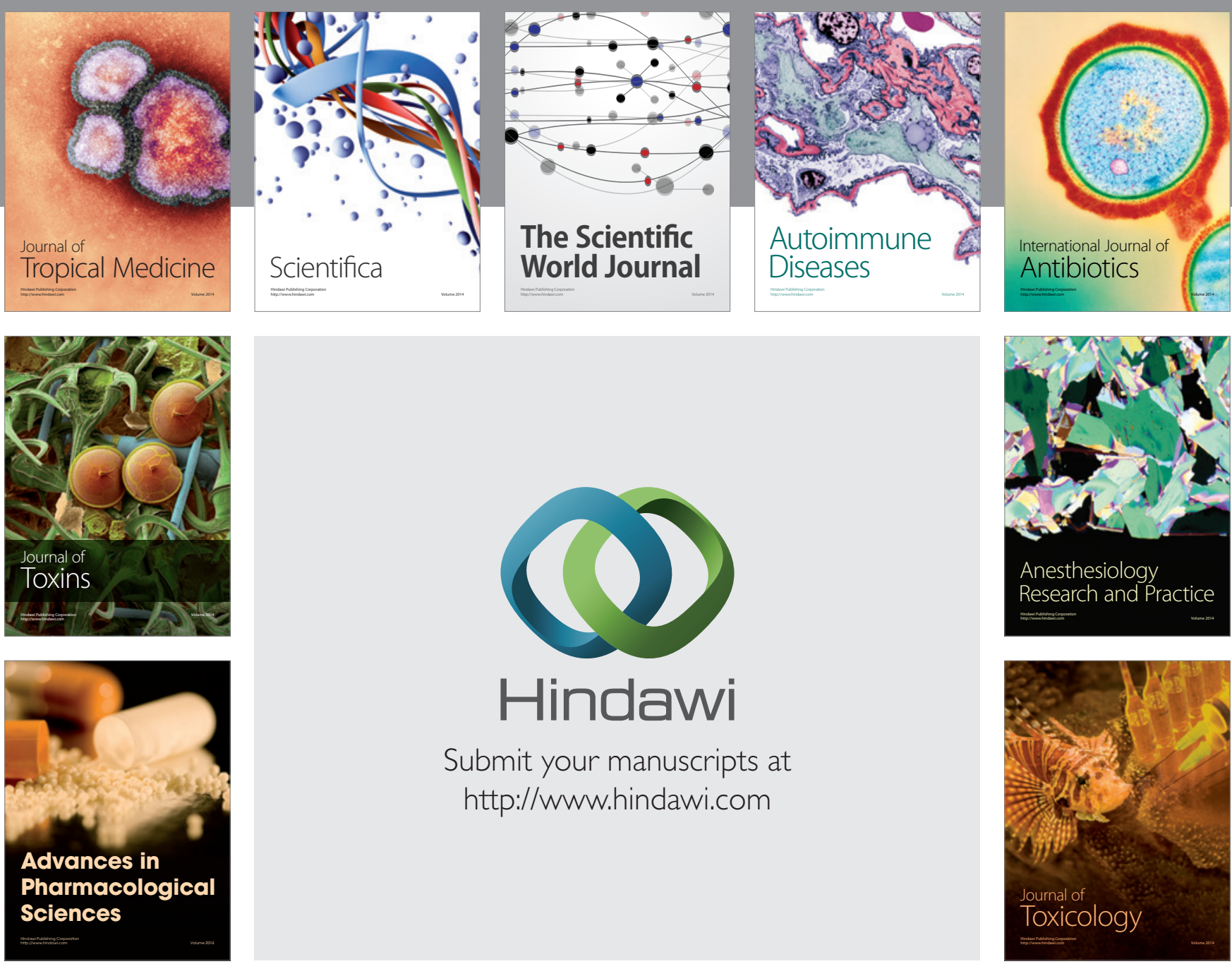

\section{Hindawi}

Submit your manuscripts at

http://www.hindawi.com
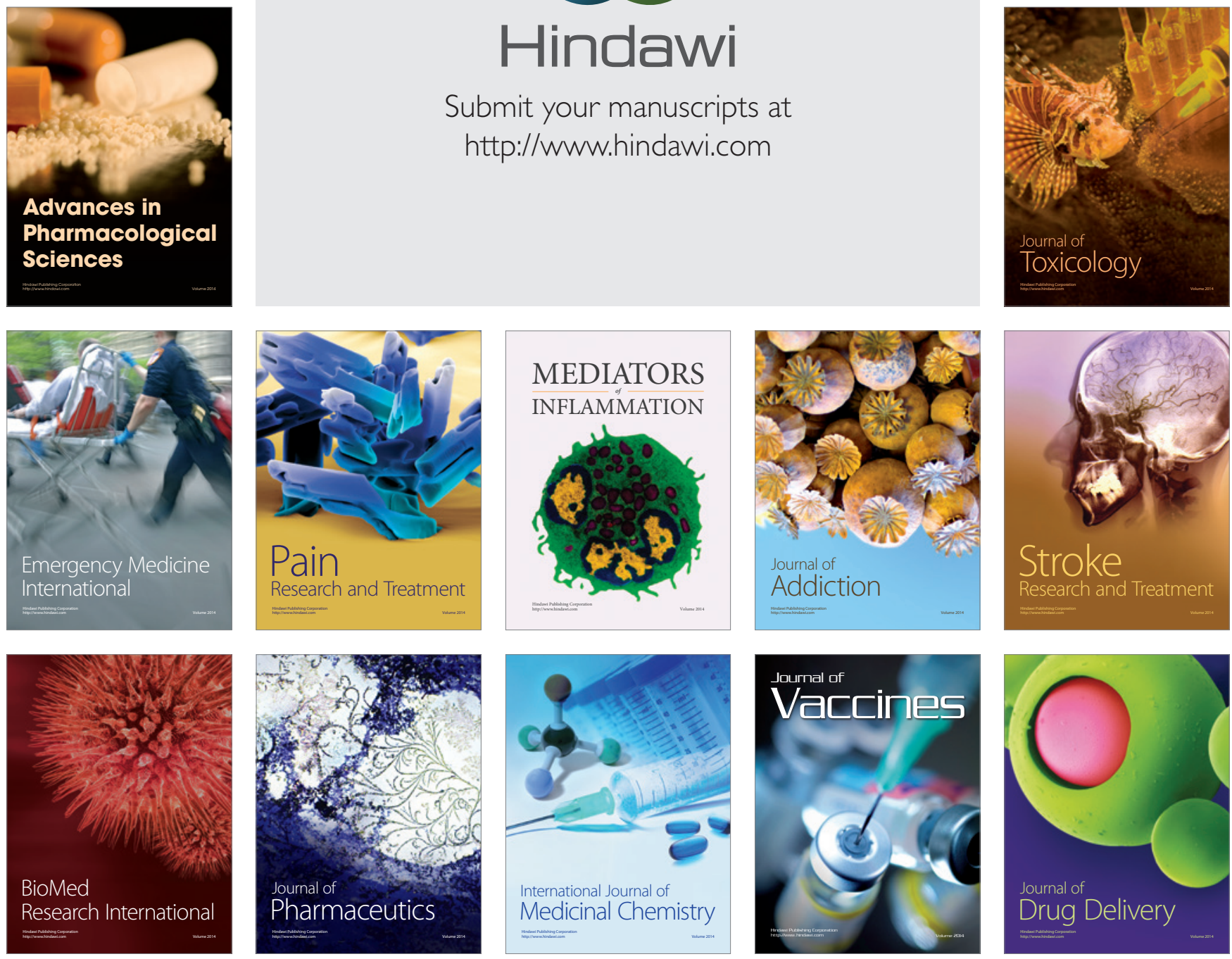